\title{
ALGUNHAS DIVERSIDADES INTERNAS NA GALICIA DOS SÉCULOS XVI-XIX: \\ O HÁBITAT, O SISTEMA AGRARIO E A HERDANZA
}

\author{
Pegerto Saavedra
}

Universidade de Santiago de Compostela

O feito de que ao longo dos séculos XVI-XVIII numerosas persoas de variada condición considerasen que Galicia era un territorio ben diferenciado social, política e culturalmente non significa que moitas delas non recoñecesen ao mesmo tempo a existencia de varias diversidades internas. Había dentro do Reino, por así dicilo, fronteiras físicas, e tamén fronteiras culturais, non sempre doadas de inventariar e de establecer, pero que daban orixe á formación parcial de identidades ou á conciencia de diferenzas locais e comarcais en asuntos como a organización familiar, os sistemas de herdanza ou inclusive a alimentación.

Nos escritos de galegos, de viaxeiros e de persoas vinculadas á administración política e relixiosa, atópanse con facilidade testemuños tanto da unidade coma das diversidades internas. Miguel Bañuelos, por exemplo, un coñecido intendente do Reino, afirmaba con rotundidade que Galicia se diferenciaba de calquera outro territorio de Europa occidental:

(...) ni los mapas ni las descripciones geográficas pueden dar cabal idea de la constitución local y población de este derramado País, cuyas entrañas son muy diferentes no solo de las demás provincias de España, pero de las extranjeras de Europa, y sólo la de Normandía de Francia suponen que tiene tal cual analogía, según los viajeros ${ }^{1}$.

Poucos anos despois o crego X. A. Posse (Herr 1984: 21), nado en Vimianzo, conta a impresión que lle causou saír de Galicia e internarse na provincia de León:

1 Así consta nun resumo de textos de Miguel Bañuelos contido no Arquivo Histórico Nacional (Madrid), mazo 2919-21920.

R. Álvarez, F. Dubert, X. Sousa (eds.): Lingua e Territorio Santiago de Compostela: ILG/CCG, 2006, 103-129 ISBN 84-96530-20-5 
Todos los objetos que veía eran tan diferentes de los de mi tierra que creía hallarme en un nuevo mundo. Bueyes, carros, montes, árboles, comidas, vestidos, lenguaje, todo se me figuraba y era realmente diverso.

Pola súa banda, os viaxeiros apreciaban a forte personalidade de Galicia, con independencia de que establecesen a fronteira leste na Cruz de Ferro ou en Pedrafita. As opinións que amosaron sobre o país e as xentes dependen da época na que nos visitasen, das comarcas que percorresen e do lugar do que procedesen. Sirva de exemplo Cosme III de Medici, que, en marzo de 1669, chega a Tui para pasar a Pontevedra, Redondela, Santiago e A Coruña. Camiña, polo tanto, pola Galicia máis poboada, pero a el, acostumado aos refinamentos de Florencia, parécelle case un deserto e un mundo sen cidades. Só loa, de oídas, as terras vitícolas de Ourense, porque o viño era un cultivo nobre, e un Medicis non podía apreciar nin o centeo nin o millo (Neira 2004).

En xeral, os viaxeiros, a pesar de chegar a un país no que se vivía pobremente, manifestaron unha opinión dos galegos menos negativa que a que corría nos séculos da Idade Moderna na literatura aldraxante, cando se foron perfilando os bumores das diferentes nacións, correspondéndolles aos galegos, a xuízo de Gracián, o de cuitados. Houbo viaxeiros que repararon mesmo nas diversidades internas que atopaban na paisaxe, nas densidades de poboación, no sistema agropecuario e ata no vestido e na faciana das xentes (cf. García Mercadal [1999] e Alonso Montero [1974]). Os naturais eran tamén conscientes destas e outras diferenzas, que en ocasións marcaban fronteiras culturais e estaban na raíz das valoracións positivas ou negativas de xentes e costumes comarcais. Pénsese, por exemplo, nos cualificativos negativos que os veciños de Tabeirós aplicaban aos cambotes que viñan traballar na sacha do millo e nas vendimas (notábanos na segunda metade do XIX de sucios e incivilizados).

Podemos pensar que determinadas diversidades, que hoxe semellan moi evidentes, existían xa nas épocas medieval e moderna, ou inclusive antes. Pero iso non acontece en todos os casos, polo menos por completo. Repárese, senón, nas estruturas do hábitat: na actualidade, resultan claras as diferenzas entre o litoral, cos vales fluviais próximos ao Atlántico, onde a ocupación do espazo é moi intensa e non sempre resulta doado diferenciar unha aldea doutra; a Galicia das montañas setentrionais, con aldeas moi pequenas; a central -principalmente, a 
antiga provincia de Lugo- en núcleos de 5-10 veciños, pero ben individualizados, e unha importante presenza de caserías illadas; e a provincia de Ourense, con lugares moito máis grandes e agrupados que os das terras luguesas. Porén, no século XVI, as cousas non eran exactamente iguais, e o hábitat da provincia de Tui, por exemplo, estaba formado por pequenos asentamentos moi afastados uns doutros, de maneira que o bispo da diocese lle propoñía a Felipe II, en 1587, a conveniencia de facer reducións coma as que se levaran a cabo nas Indias e, ao parecer, en Guipúscoa:

(...) estos feligreses, con ser tan pocos en cada una de las feligresías, no viven junto a la iglesia por la mayor parte, ni circunvecinos, si no un cuarto de legua, y media, y una de la iglesia y apartados unos de otros (...), y si su Magestad fuese servido de reducirlos a poblaciones, como se hizo en la provincia de Guipúzcoa, sería el mayor servicio de Dios que se podría hacer y aun de su Magestad, para que esta gente bárbara fuese política y doméstica y enseñada en la doctrina cristiana, que viviendo como viven es imposible. (Ruiz Almansa 1948: 76)

Algo semellante se podería dicir do sistema agropecuario, que se transformou radicalmente entre 1600 e 1800 , con resultados, nuns casos, de acentuar diferenzas comarcais e, noutros, de amortecelas.

Doutra banda, para explicar moitas diversidades internas, desde a metroloxía ata algunhas variantes dialectais, sería preciso estudar o proceso de organización do territorio por parte dos diferentes poderes -O eclesiástico, o señorial e o real-, pois a súa vixencia creaba no interior de Galicia numerosas fronteiras, algunhas moi permanentes; fronteiras entre as dioceses, pero tamén entre os arciprestados e as parroquias. Estas constituían a única rede administrativa que cubría de xeito regular e uniforme todo o territorio. Creadas en plena Idade Media, cada unha co seu patrón, manteñen unha grande estabilidade ata o día de hoxe, a pesar dos cambios demográficos extraordinarios que tiveron lugar ao longo dos séculos (cf. Fariña Jamardo [1996]). Desde comezos da Idade Moderna ata os arranxos parroquiais de fins do XIX, as modificacións foron escasísimas, e a cartografía actual permite diferenciar unha área de parroquias extensas, que cobre toda a Galicia do norte, do oeste e do sur, e a de parroquias moi pequenas, que se corresponde basicamente coa diocese de Lugo, agás as montañas orientais (vid. as derradeiras medicións dirixidas por Precedo e Gallego [2001]). Isto, no tocante á 
superficie das circunscricións, pois o número de fregueses variou moito: as parroquias de Tui tiñan moi poucos a fins do XVI -segundo recoñecía o bispo no documento de 1587 citado-, pero eran das máis poboadas a mediados do XVIII, e polo tanto das máis ricas no referido ao valor dos décimos, e por iso moi solicitadas polos curas ( $\mathrm{O}$ valor dos décimos pertencentes aos curas, segundo as dioceses, en Rey Castelao [1992]).

A división do territorio en xurisdicións e coutos, na meirande parte dos casos de carácter señorial, mantivo, asemade, unha longa vixencia, pois foise configurando na Idade Media e non desapareceu ata a década de 1830, co establecemento da administración local liberal baseada nos municipios e partidos xudiciais. As doazóns reais permitiron a consolidación dos grandes patrimonios das institucións eclesiásticas, patrimonios materiais -terras e rendas-e inmateriais -exercicio do poder político en ámbitos demarcados-; nos derradeiros séculos da baixa Idade Media, tamén por doazóns, adquisicións, trocos, ou a través das usurpacións violentas, constituíronse os patrimonios das casas da aristocracia, nas que as facultades señoriais -exercicio do poder, cobro de prestacións aos vasalos, aínda que non fosen colonos- eran moi importantes (A situación a mediados do XVIII en Eiras Roel [1989: 113-135] e Río Barja [1990]).

A resultas do proceso de señorialización, que afectou ao noventa por cento do territorio, os mosteiros primeiro e os castelos despois tiveron unha función decisiva na organización dun espazo que quedou dividido en centos de coutos e xurisdicións de moi diferente tamaño, en ocasións sen continuidade xeográfica, pero sempre ben demarcadas unhas das outras, e unha das principais obrigas dos xuíces ordinarios era precisamente vixiar e conservar os límites, pois xurisdición e coutos constituían as divisións da administración señorial e os chantos que os separaban viñan ser verdadeiras fronteiras que xebraban poderes, territorios e obrigas, e os pontádegos e portaxes, a xeito de aduanas, que existían en moitas, testemuñan ese carácter de fronteira entre espazos que pertencían a poderes distintos (un mapa das portaxes e pontádegos que existían na segunda metade do XVIII en García Lombardero [1973: 68].

As doazóns, compravendas, trocos e usurpacións deron orixe a xurisdicións e coutos de tamaño moi diferente: ora se compoñían de ducias de parroquias, ora de só unha aldea, situación esta que foi moi criticada por xuristas do século XVIII, defensores dunha administración 
local máis homoxénea e controlada polo poder real. Non obstante, a división do territorio que quedara consolidada conforme se estenderan os poderes señoriais por todo o Reino era moi ríxida: o poder que se exercía sobre unha determinada xurisdición pertencía ao patrimonio dun señor, un bispo, un mosteiro, un nobre, e facer unha nova reordenación ou división do espazo significaba desamortizar eses poderes, cousa que só puideron facer as Cortes de Cádiz en 1811 (Saavedra 2003). En teoría, a xente movíase libremente dunhas a outras xurisdicións, á hora de casar, de tomar terras en foro ou de exercer oficios; pero uns marcos tan abundantes e ao mesmo tempo tan ríxidos tiveron que favorecer diversidades mal coñecidas, por pouco estudadas: a posible relación que existe entre variacións na metroloxía e a división xurisdicional merecería, por exemplo, ser investigada; tamén variantes dialectais vinculadas á vixencia de determinadas cargas señoriais, á dependencia dunha determinada institución rendeira ou doutra. Como queda dito, o réxime señorial, tan complexo, supoñía a existencia de moitas fronteiras internas, máis ou menos operativas pero que, ao se manteren en vigor séculos, puideron crear hábitos particulares vinculados a sometementos múltiples, á celebración regular de xuntas de cabezas de casa, etc. (merecería ser investigada en particular a relación entre fragmentación xurisdicional e variacións na metroloxía; un inventario das diversas medidas de superficie e capacidade desde mediados do XVIII ao século Xx en Fernández Justo [1986]).

A división do territorio orixinada pola implantación dos poderes señoriais, e debido a que esta nacenza era irregular, ríxida e moi permanente, serviulle de base á monarquía para crear pequenas demarcacións fiscais que recibían o nome de partidos e que, en xeral, aínda que non sempre, se formaron a través de subdivisións de xurisdicións e coutos. O feito de que mesmo a fins do XVIII algúns partidos da provincia de Lugo se denominen «coto de...» (en moitos casos), «Abadía de Sobrado», «Caseros de Diego Sánchez» ou «Tierrachá de Olinda López» é unha proba de que a monarquía, á hora de organizar o territorio en circunscricións, en principio para os efectos fiscais, se valeu dos marcos señoriais e, ás veces, utilizounos sen máis ${ }^{2}$ (Saavedra

2 Os partidos fiscais aínda non son ben coñecidos e non eran os mesmos para as alcabalas e para os servizos. 
1985). De calquera xeito, a influencia da administración da monarquía na vida cotiá das xentes tivo un peso moi inferior ao dos poderes señoriais, xa que eran estes os que contaban cunha rede de persoas -xuíces ordinarios, escribáns, mordomos- que chegaba a todos os recunchos.

A fragmentación do espazo en parroquias, arciprestados, xurisdicións, coutos e partidos, uns marcos moitas veces entrambilicados, pero en xeral pouco cambiantes, favorecía sen dúbida a abundancia de diversidades de tipo local e comarcal en varios ámbitos da vida colectiva, se ben no decorrer do século XVIII sobre todo a mobilidade das xentes do rural aumentou significativamente. Trátase de desprazamentos de diferente natureza: uns vinculados a traballos agrarios (das montañas aos vales); outros, á asistencia ás cada vez máis abundantes feiras e romarías; outros, a migracións a núcleos urbanos en crecemento (Eiras 1994, Dubert 2001, e Martín García 2005). Coas xentes podían viaxar usanzas e costumes locais, ou non, pois cando a mobilidade afecta principalmente aos sectores máis pobres da sociedade, estes non sempre teñen forza -e en ocasións, nin vontade- de conservar ou impoñer prácticas culturais propias.

En resumo, nun territorio tan dividido desde o punto de vista político e administrativo, e con milleiros de pequenas comunidades aldeás, parece lóxico que agromasen diversidades e inclusive identidades parciais en diferentes niveis. Pero existen algunhas grandes divisións dentro de Galicia que non respectan as demarcacións administrativas e das que vou tratar aquí: son as referidas ao hábitat, á organización agraria, aos montes comunais e ás estruturas familiares e herdanza. Segundo se verá, en cada un dos temas as fronteiras variaban e en ocasións ata cambiaron co tempo.

\section{O HÁBITAT}

As fontes estatísticas de mediados do século xx, nomeadamente o Nomenclátor de 1960, permiten comprobar o predominio dos asentamentos con menos de dez veciños nos bispados de Mondoñedo e Lugo, e dos de máis de once na Galicia occidental e na provincia de Ourense. Dentro deste cadro xeral, pódense establecer algunhas 
matizacións, seguindo a Abel Bouhier: os núcleos máis pequenos, a miúdo con menos de cinco veciños, son comúns nas montañas setentrionais e nos concellos que as circundan -desde Monfero a Ortigueira-, namentres no bispado de Lugo as aldeas teñen polo xeral de seis a dez veciños, e conforme se camiña cara ao sur, non son raras - en Chantada, Monforte ou Quiroga- as que acadan de quince a vinte e cinco. Doutra banda, se nas mariñas ártabras e nas Rías Baixas os asentamentos adoitan ter máis de vinte lumes, a súa estrutura non adoita ser compacta, senón que pode comporse de núcleos múltiples, ou adoptar a forma de aldeas de regueiro e aldeas-nebulosas, de xeito que a súa individualidade non se percibe na paisaxe tan claramente como na Costa da Morte e sobre todo na provincia de Ourense. É nesta provincia onde os asentamentos amosan un meirande tamaño, normalmente por riba dos vinte e cinco lumes, ou dos cincuenta na Limia, Verín, Viana e Valdeorras, dándose casos nos que un só núcleo de hábitat forma unha parroquia (Bouhier 2001, Souto 1982, Fariña Tojo 1980, O’ Flannagan 1996: 78 ss.).

O hábitat, de primeiras, parece un elemento moi permanente dentro da paisaxe, pois os controis que os poderes señoriais e as comunidades campesiñas tiñan sobre o espazo non facilitaban que da noite para a mañá aparecese unha aldea nova ou desaparecese unha antiga; nin sequera o establecemento dun veciño a maiores dos que xa existían era unha cuestión sinxela, xa que para iso tiña que partirse unha explotación e a miúdo os aspirantes a facer lume á parte precisaban que se lles deixase levantar un alpendre e pechar algúns anacos de monte (unha visión xeral dos problemas en Balboa [1992]).

$\mathrm{Na}$ Galicia interior, a estrutura do hábitat cambia pouco desde mediados do XVI a mediados do Xx, e as diferenzas que en 1960 había entre Lugo e Ourense neste ámbito na derradeira data existían xa catro séculos antes: en 1960, as aldeas de Samos, por exemplo, tiñan unha media de 8,5 lumes e as de Viana do Bolo, 36; en 1560, as cifras eran, respectivamente, de 7 e de 30 (Saavedra 1998: 178 ss). Se reparamos no que acontece nos concellos de Samos e Sarria entre 1590 e 1857, pode comprobarse como os cambios se reducen basicamente a un aumento do tamaño dos asentamentos, para absorber o crecemento demográfico, pero, fóra diso, nada parece mudar.En Samos, o tamaño medio das aldeas pasou, entre as dúas datas, de 7,4 a 9,4 veciños (ou a 11,8, 
se a comparación se realiza só entre as controladas en ambas as datas), sendo as de 15 e máis familias as que realmente incrementaron a súa importancia, ao acolleren, en 1857, o $57 \%$ da poboación (fronte a só o $31,5 \%$ en 1590). A proporción de casaríos illados apenas se modificou e, tanto a finais do XVI como a mediados do XIX, os veciños que vivían neles non chegaban ao $2 \%$ do total. Sarria presenta algunhas diferenzas co concello de Samos (malia ser fronteirizos), que se conservaron ao longo do tempo: un menor tamaño medio dos núcleos e unha forte presenza dos casaríos illados, que representaban un $23,7 \%$ das entidades en 1590 e un 25,6 en 1857, aínda que os veciños que residían neles non supoñían o $6 \%$ do total. Tamén neste municipio aumenta a dimensión das aldeas, de 4,3 a 6,3 veciños, debido a que no transcurso da Idade Moderna se consolidaron núcleos con vinte ou máis familias, inexistentes na segunda metade do XVI.

\begin{tabular}{|c|c|c|c|c|c|c|c|c|}
\hline \multirow[b]{2}{*}{ Veciños/aldea } & \multicolumn{4}{|c|}{ Samos } & \multicolumn{4}{|c|}{ Sarria } \\
\hline & $\begin{array}{l}\% \text { aldeas } \\
\text { en } 1590\end{array}$ & $\begin{array}{c}\% \\
\text { poboación }\end{array}$ & $\begin{array}{l}\% \text { aldeas } \\
\text { en } 1857\end{array}$ & $\begin{array}{c}\% \\
\text { poboación }\end{array}$ & $\begin{array}{l}\% \text { aldeas } \\
\text { en } 1590\end{array}$ & $\begin{array}{c}\% \\
\text { poboación }\end{array}$ & $\begin{array}{l}\% \text { aldeas } \\
\text { en } 1857\end{array}$ & $\begin{array}{c}\% \\
\text { poboación }\end{array}$ \\
\hline 1 & 9,9 & 1,3 & 11,9 & 1,3 & 23,7 & 5,7 & 25,6 & 4,1 \\
\hline 2 & 12,3 & 3,4 & 9,2 & 1,9 & 20,7 & 9,9 & $14,-$ & 4,5 \\
\hline 3-4 & 14,8 & 7,4 & 14,7 & 5,3 & 21,5 & 17,2 & 16,9 & 9,3 \\
\hline $5-6$ & 17,3 & 12,6 & 10,1 & 5,6 & 11,9 & 15,5 & 9,7 & 8,6 \\
\hline 7-9 & $16,-$ & 16,9 & 14,7 & 12,6 & 13,3 & 24,5 & 10,4 & 12,8 \\
\hline $10-14$ & $16,-$ & 26,7 & 12,8 & 16,2 & 5,2 & 13,5 & 12,3 & 22,5 \\
\hline $15-19$ & 11,1 & 24,8 & 17,4 & 31,5 & 3,7 & 13,7 & 5,1 & 13,6 \\
\hline $20-29$ & 2,5 & 6,9 & 6,4 & 16,5 & - & - & 4,5 & 16,1 \\
\hline $30-39$ & - & - & 2,8 & 9,1 & - & - & 0,9 & 4,2 \\
\hline $40 \mathrm{e}+$ (Samos) & - & - & - & - & & & & \\
\hline 40-49 (Sarria) & & & & & - & - & 0,6 & 4,3 \\
\hline 50 e + (Sarria) & & & & & - & - & - & - \\
\hline \multicolumn{4}{|c|}{ Media de veciños por aldea } & \multicolumn{3}{|c|}{1590} & \multicolumn{2}{|c|}{1857} \\
\hline \multicolumn{4}{|l|}{ Samos } & \multicolumn{3}{|c|}{7,4} & \multicolumn{2}{|c|}{$9,4(11,8)$} \\
\hline \multicolumn{2}{|l|}{ Sarria } & & & \multicolumn{3}{|c|}{4,3} & \multicolumn{2}{|c|}{$6,3(7,2)$} \\
\hline
\end{tabular}

Cadro 1. Evolución do hábitat en dous concellos limítrofes da Galicia interior, Samo e Sarria. Fonte: arquivo xeral de Simancas, "Exps. de Facenda", mazos 97/76 e 97/86, e Boletín Oficial da Provincia de Lugo, 1858.

Os datos doutros concellos que puidemos analizar confirman a permanencia dos trazos básicos do hábitat da Galicia interior. Na terra de Cervantes, por exemplo, os casaríos illados apenas teñen importancia como entidades de habitación, tanto en 1561 como tres séculos despois, e o crecemento demográfico afecta tan só ao tamaño medio dos asentamentos, que pasan de 4,7 a 8,7 veciños nesas 
tres centurias. No Courel tampouco existían casaríos illados en 1580, cando as aldeas tiñan unha media de 19,8 fogares. En 1857, esta cifra elevarase a 24,6 e os novos casaríos que rexistra o Nomenclátor correspóndense con oito ferrerías (coa súa casa de administración) e unha reitoral. No concello de Navia de Suarna a evolución na fase final do Antigo Réxime é parecida: en 1709, nas aldeas residían, por termo medio, 8,4 veciños e en $1857,11,3$; de xeito que, se na primeira data só un $27 \%$ da poboación pertencía a entidades de quince ou máis fogares, a mediados do XIX esa porcentaxe ascendía a 55. Por fin, as permanencias parecen tamén notables na provincia de Ourense, dado que nalgunhas das súas circunscricións os núcleos acadaban dimensións considerables dentro do contexto galego, que constitúen, en palabras de A. Bouhier, «des villages à la galicienne» (Bouhier 2001: I 460 ss). Así, no Bolo, o tamaño medio das entidades era de 31 veciños en 1557 e de 46 en 1752, sen que nin nunha nin na outra data as fontes mencionen casaríos illados ${ }^{3}$.

O número de aldeas controladas pasou de 73 en 1582 a 76 en 1752, pero o tamaño medio dos asentamentos aumentou dos 6,5 lumes na primeira data a 20,3 na segunda, ou sexa unha multiplicación por 3,25. Algo parecido aconteceu nas terras tudenses, pois no Val Miñor, nos concellos de Valadares e Porriño e no Val de Manoo o número de veciños multiplicouse por 4,5 entre 1561 e 1752, de xeito que se volveron innecesarias as reducións que solicitaba en 1587 o bispo Torquemada. A provincia converteuse nun formigueiro humano, e en 1865 unhas tres cuartas partes da poboación residían en núcleos de 15 ou máis familias ${ }^{4}$.

A Galicia litoral aparece na época contemporánea como zona de aldeas grandes, en ocasións comparables en tamaño ás de comarcas de Ourense, aínda que con estruturas menos compactas, segundo quedou indicado. Abel Bouhier sinala que cara a 1960 -e polo tanto antes da actual urbanización difusa- o hábitat constituía nas comarcas de elevadas densidades de poboación das rías un verdadeiro labirinto. Pero, se imos a mediados do XVI, podemos comprobar que daquela a estrutura dos

3 Os datos do Bolo no século XVI no arquivo xeral de Simancas, Exps. de Facenda, mazo 95/82.

4 Arquivo xeral de Simancas, Exps. de Facenda, mazo 97/87, e Avila/La Cueva (1995). 
asentamentos presentaba nesas zonas características semellantes ás das montañas setentrionais, pois os datos dispoñibles apuntan a que nas rías e na terra tudense predominaban antes de 1600 as pequenas aldeas de un a catro veciños. Véxase o caso do Salnés:

\begin{tabular}{|c|c|c|}
\hline Tamaño veciños & $1582 \%$ aldeas & $1752 \%$ aldeas \\
\hline $1-2$ & 26,0 & 1,3 \\
$3-4$ & 24,7 & 1,3 \\
$5-9$ & 31,5 & 23,7 \\
$10-14$ & 10,9 & 22,4 \\
$15-19$ & 1,4 & 10,5 \\
$20-24$ & 4,1 & 11,9 \\
$25-29$ & $1,-4$ & 11,9 \\
$30-39$ & - & 7,9 \\
$40-49$ & - & 2,6 \\
$50-59$ & - & 1,3 \\
$60-69$ & - & 1,3 \\
$70-79$ & - & 2,6 \\
$80 \mathrm{e}+$ & & 1,3 \\
\hline
\end{tabular}

Cadro 2. Evolución dos asentamentos rurais no Salnés. Tomado de Fernández Cortizo (1994).

En resumo, na Galicia occidental pasouse entre o século XVI e o XVIII dun hábitat de pequenos asentamentos dun a catro veciños a outro no que as aldeas dese tamaño deixaron case de existir por se teren multiplicado o número de lumes. Iso significa que durante a época moderna se consolidou a comunidade aldeá, pois non era o mesmo vivir nun núcleo de dúas ou tres familias que nun de dez ou vinte. Os intercambios de todo tipo, desde os relacionados coas axudas mutuas ata os que tiñan que ver co mercado matrimonial, reforzáronse. Nas rías, nos vales fluviais do Ulla, Umia, Lérez, etc., e nas terras tudenses é onde este proceso de consolidación das aldeas -e da intensificación da vida comunitaria- foi máis radical, pero agás nas montañas setentrionais o mesmo tivo lugar no resto de Galicia, pois en todas as comarcas aumentou máis ou menos o número de veciños. Ramón Otero Pedrayo (1969), coa súa fina sensibilidade, apreciou ben o vigor da vida aldeá no solpor barroco:

$\mathrm{Na}$ Galiza do século XVIII -afirma-, a pesares das fábricas de «indianas», das novas labouras do liño, alenta inteira a aldea, disposta en rica variedade de acomodaciós, perfil do estado da longa e xornaleira polémica ca terra, co mar, cos «donos da terra», conforme inza na mariña, no val, na bocarribeira, na montana ou na Serra (...). De certo, logo dixire as novedás. Cóceas no seu podente estómago. Pola mesma forteza da súa raís, non a abanean os ventos de lonxe. Doadamente se inxiren nela o liño do Báltico, o millo, a pataca. 


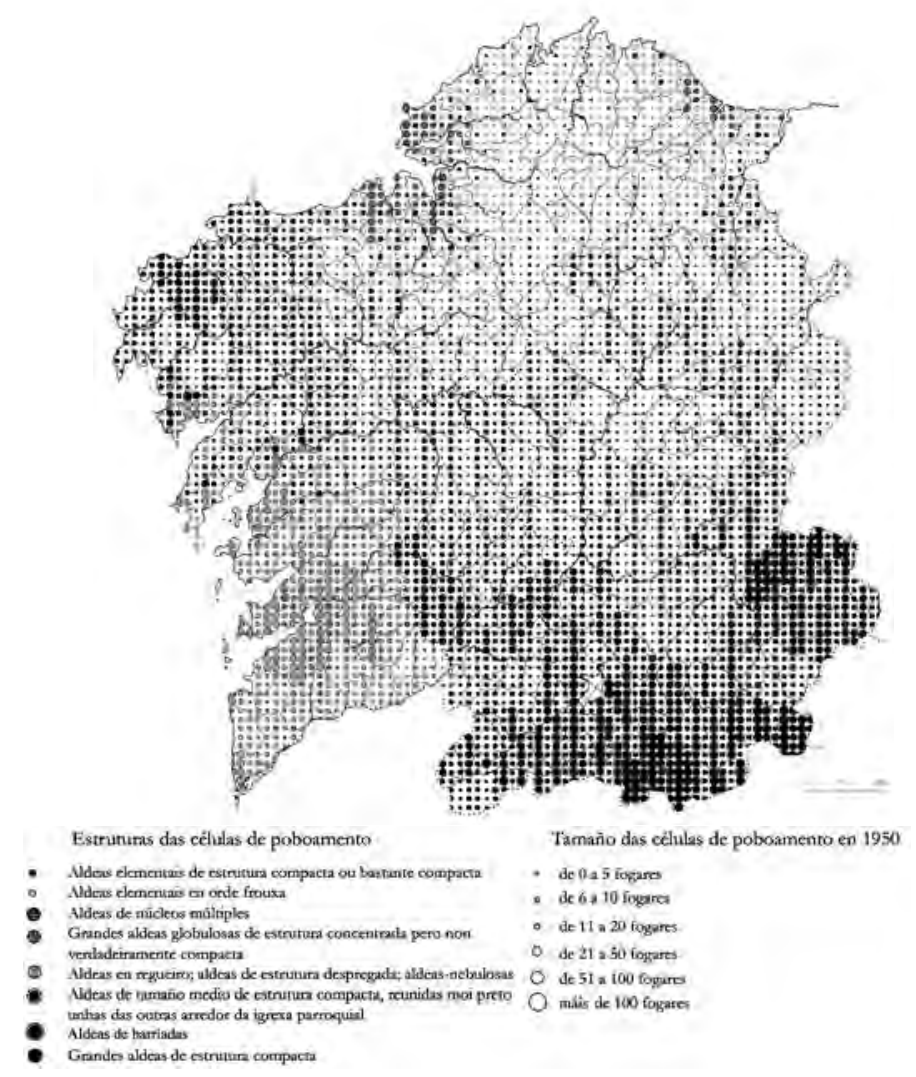

Mapa 1. Distribución do hábitat, tamaño e estruturas das células de poboamento. Tomado de A. Bouhier (2001: mapa 6).

O estudo da estrutura e tamaño do hábitat pon de manifesto que desde o século XVI ao XX se mantiveron determinadas diferenzas, relacionadas coa estabilidade dos asentamentos nas antigas provincias de Lugo e Ourense; en troques, no litoral e prelitoral xurdiron realidades novas, orixinadas polo intenso crecemento demográfico e polas transformacións radicais do complexo agropecuario. Pero, máis alá do aspecto formal do tamaño e disposición das aldeas, existen realidades de tipo cultural que non sempre resulta doado apreciar: as elevadas densidades demográficas da Galicia occidental, a intensa ocupación do solo e a escasa individualización das aldeas en ocasións reforzaron, ao meu 
xuízo, a sociabilidade dentro do marco parroquial e, en definitiva, o papel da parroquia nos ámbitos económico, social e cultural, sendo a pertenza a ela un importante factor de identidade. En certo modo recoñecía esta situación o comisionado encargado de facer o Catastro de Ensenada na provincia de Santiago. Cando operaba nas parroquias da ría de Pontevedra solicitoulles aos membros da Real Junta de la Única Contribución que lle autorizasen prescindir dos datos tocantes ás distancias existentes entre as leiras e as aldeas ás que pertencían, co seguinte argumento:

(...) respecto esta tierra es diversa de las Castillas o otros vecinos, en que los lugares estaban formados y en unida población (...), acá son cortos y bien conocidos los términos de cada feligresía, cuyas casas que componen una diversa población, aunque estén distantes unas de otras, y son como cortijos o alquerías, que aquí llaman lugares, son los mismos que dan nombre y vecindario a la propia feligresía y forman su esparramada consistencia, sin haber población y parte principal a que poder adscribir la distancia, porque cualquier casa y sus contiguas tierras son parte de aquel todo que se denomina feligresía 5 .

No reforzamento das diversas funcións da parroquia e no proceso da súa consolidación como factor de identidade na Galicia occidental, influíron os cambios no hábitat e nas densidades demográficas e tamén a actuación das autoridades eclesiásticas, que obrigaron aos veciños a concorrer á igrexa con regularidade e estimularon a fundación de confrarías e a devoción ao patrón da freguesía. As mesmas iniciativas tomaron os bispos de Mondoñedo, Lugo e Ourense, pero na Galicia interior as aldeas, distantes e individualizadas, competían coa parroquia en canto centros de sociabilidade e ámbitos de identidade, e en moitas delas xurdiron capelas nas que se celebraba una festa anual e casaban moitas parellas, no canto de facelo na igrexa parroquial ${ }^{6}$. Penso, con todo, que varias destas cuestións, e, principalmente, a diversa relevan-

5 Arquivo Xeral de Simancas, Dirección Xeral de Rendas, $1^{a}$ Remesa, mazo 1874 (1752).

6 A celebración de vodas nas capelas, en particular na Galicia oriental, está ben acreditada nos libros de matrimonios que se conservan na actualidade nos arquivos diocesanos. Un exemplo entre moitos, os correspondentes á freguesía de Conforto, na actualidade do bispado de Mondoñedo. 
cia da parroquia -no espazo e no tempo- como factor de identidade merecería un estudo demorado ${ }^{7}$.

\section{A ORGANIZACIÓN AGRARIA}

No tocante á organización agraria e ao que cómpre chamar complexo tecnolóxico agropecuario, poden apreciarse no interior de Galicia diferenzas que en ocasións se mantiveron tamén ao longo de séculos, a pesar dos cambios nos tipos de cultivos e nos sistemas de rotacións. É preciso volver de novo nestes aspectos aos estudos de Abel Bouhier, quen puxo de manifesto como a mediados do Xx predominaba na meirande parte do territorio a distribución das labranzas en agras, ou sexa, o agrupamento das terras de cultivo de cada aldea en varios bloques, choídos con paredes ou sebes e constituídos interiormente por leiras e tallos, abertos de diversos posuidores, que se valían de chantos ou estacas para coñecer os lindeiros. A denominación deses bloques, que non deben asimilarse propiamente nin ao bocage nin ao openfield, variaba dunhas partes a outras sen que a realidade nominada cambiase apenas: así, dicíase chausa, veiga ou vilar na mariña cantábrica; estivo no concello de Burón (e tamén barbeito); veiga ou praza na Limia e Celanova; barbeito en Maceda e Caldelas; agro nun amplo espazo central, desde Os Ancares a Trives e por occidente ata Tabeirós, e agra noutra franxa delimitada polo leste polos concellos da Pastoriza e Baleira, e que chegaba a Fisterra (de Bergantiños a Noia) (Bouhier 2001).

Fóra da zona das agras quedaban outros tipos de organización dos eidos que abarcaban pouca superficie, pero que tiñan características moi especiais: os socalcos e bancais das mariñas de Betanzos e das Rías Baixas, comarcas de elevada densidade de poboación e terrádego moi parcelado; os eidos pechados das montañas setentrionais - comarcas da Mariña occidental e Ortegal-, que si constituían un verdadeiro bocage; e os grandes campos abertos ou openfields do sueste (Verín, Viana e Valdeorras). Nas proximidades das Mariñas de Betanzos e das Rías

Pois o coñecido libro, xa citado, de Fariña Jamardo (1996) non aborda estes problemas, que teñen que ver coa estrutura do hábitat, cos diversos niveis de sociabilidade e coa presión de autoridades eclesiásticas. 
Baixas, as agras coexistían con eidos pechados e socalcos, e estes tamén predominaban nas terras de viñedo dos vales do Sil e do Miño.

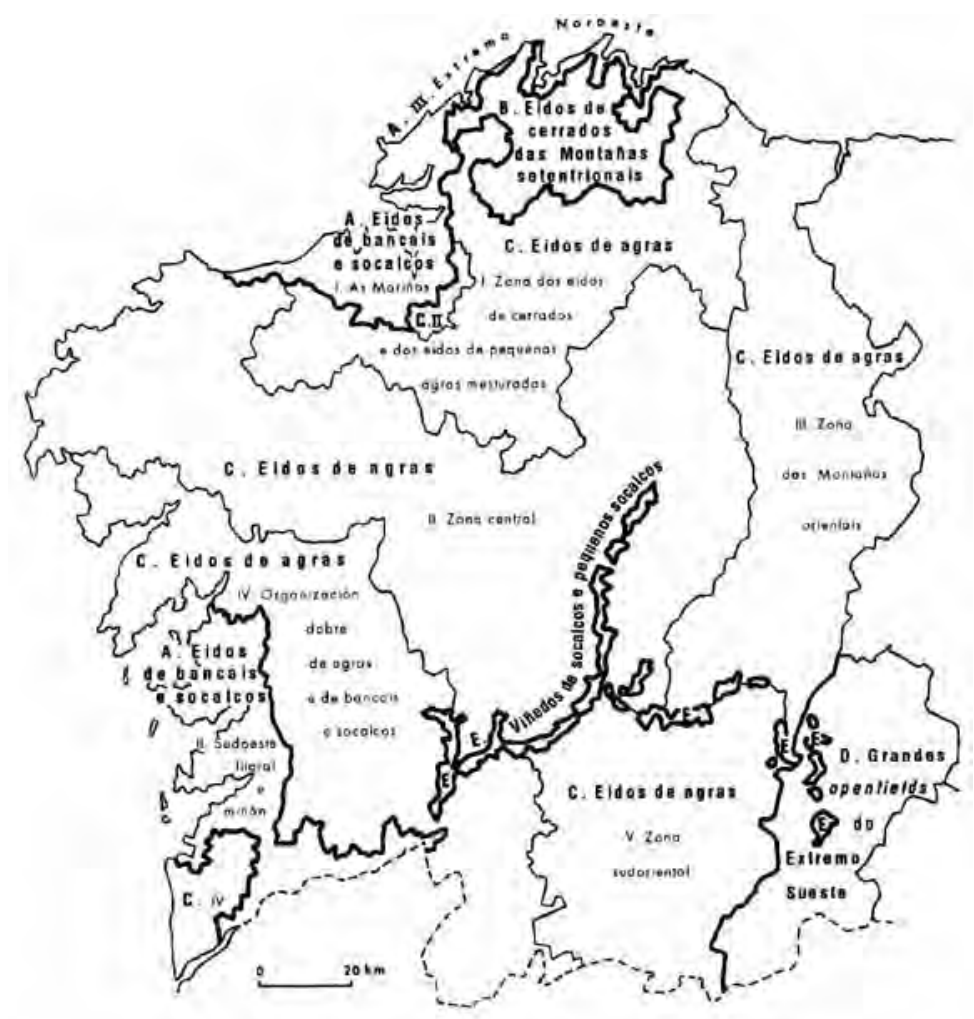

Mapa 2. Distribución xeral das diferentes formas de organización agraria. (Tomado de A. Bouhier [2001: 106]).

En realidade, tendo en conta que os eidos e bancais do litoral eran resultado, no litoral, da desarticulación de antigas agras, e que as terras de viñedo tiñan características particulares, pode dicirse que había dentro de Galicia, no referido á organización agraria, tres zonas ben diferenciadas: a das agras, con moito a máis extensa, a de bocage das montañas setentrionais, e o extremo sueste de openfields. Se quixésemos poñer esta división en relación coa estrutura do hábitat, a conclusión sería que o bocage correspondese coa zona de asentamentos máis pequenos e espallados, e ao revés, o openfield coas grandes aldeas de Ourense, pero as agras existen tanto en comarcas de aldeas grandes (A Limia, 
Maceda, Courel, Costa da Morte), como de aldeas pequenas (Terra Chá, Mariña oriental, Lugo...). Polo mesmo, a correspondencia entre hábitat e organización agraria é significativa nuns casos e só parcial noutros.

A organización en agras, que cara a 1600 predominaba tamén nas Rías e Mariñas (non nas comarcas de bocage nin de openfield), tampouco se correspondía nin na época moderna nin no século Xx co sistema de cultivos. Neste aspecto, a principal división interna viña determinada primeiro pola xeneralización do millo miúdo e despois pola do millo americano. Isto quere dicir que a Galicia litoral e prelitoral e os vales fluviais do suroeste -nomeadamente o do Miño, ata Ourense-, se caracterizaban antes do millo americano por un sistema agrario con certo grao de intensidade, no que en moitas terras alternaban os cereais de inverno e o millo miúdo (daquela simplemente millo). Pola contra, en toda a antiga provincia de Lugo, en boa parte da de Ourense e nas terras máis interiores de Betanzos, Mondoñedo e Santiago, sementábanse centeo os anos pares ou impares, ou sexa, unha agra cultivábase un ano si e outro non ${ }^{8}$.

O primeiro resultado da expansión do millo americano foi acentuar a diferenza que existía entre as dúas Galicias, pois o novo cereal sementouse en principio no canto do millo miúdo, permitiu un aumento da produtividade da terra e favoreceu un forte crecemento da poboación -cos cambios no hábitat antes mencionados-. En consecuencia, as comarcas do litoral, prelitoral e vales fluviais acadaron un meirande peso demográfico e a mediados do XVIII ofrecían unha paisaxe moi bumanizada, que contrastaba coa do interior, menos poboado e con máis superficie dedicada a monte. Naturalmente, estas diversidades no complexo agropecuario acompañábanse doutras na alimentación: os labregos do interior comían pan de centeo e dispoñían de máis recursos gandeiros, desde leite a carne e queixo, namentres os do litoral se alimentaban de boroa, mesturándolle, cando podían, algo de centeo, e as racións de carne e leite andaban máis taxadas que nas montañas (Villares 1972, Sobrado 2002).

O cultivo da pataca, que principiou a acadar importancia na segunda metade do XVIII ratificou, se se quere, as diferenzas territoriais xa

8 Cf. Pérez García (1982: 87-104); Saavedra (1999: 63-108). Sobre as denominacións do millo americano, R. Álvarez Blanco (2002: 69-94). 
vistas, pois a nova planta sementouse pouco a pouco nas agras que antes descansaban un ano de cada dous. Nas comarcas do millo tiña a entrada menos doada, porque as épocas de sementeira e recolleita da gramínea e do tubérculo viñan coincidir, e os labregos, por rendibilidade e polo escaso aprecio social da pataca, preferían a boroa. Así, a Galicia do centeo foise convertendo tamén en Galicia pataqueira, fronte á do millo, pouco amiga das entón chamadas a miúdo castañolas mariñas ou de Indias. Sen dúbida, dito de xeito tan rotundo, todo iso simplifica un pouco a realidade, pois nin os vales do interior descoñecían o millo -polo menos, desde mediados do XVIII- nin as terras do litoral as patacas -no decorrer do XIX-, pero si é certo que o millo, a pataca e o centeo tiñan no sistema de cultivos e na alimentación unha importancia moi desigual nunhas e noutras comarcas galegas?.

Cómpre chamar a atención sobre o feito de que, a pesar das transformacións que para o sistema agrario representaron o millo e a pataca -cambios que se acompañaron doutros na composición da cabana gandeira e no cultivo de forraxes-, a organización de agras mantívose, agás nas Rías Baixas e Mariñas, onde foi substituída polos bancais e socalcos. Non sen conflito, por servidumes de paso e pasto, os labregos conseguiron pórse de acordo para cambiar as rotacións, que se fixeron máis breves, namentres se reducía o tempo que as terras quedaban de folgado para uso comunitario. As innovacións agrarias non implicaron, ao revés do que en ocasións se ten afirmado, un proceso de individualismo agrario, senón que supuxeron unha meirande necesidade de acordos entre os veciños das aldeas que tiñan cada vez máis lumes e dentro dos que se intensificaba a vida comunitaria e as interdependencias que implicaba ${ }^{10}$.

Inclusive alí onde as leiras se dividían e multiplicaban, as agras quedaban como algo permanente, co seu nome, e nas que localizaban as parcelas dos veciños. Así o recoñecía o comisionado do Catastro de Ensenada ao que fixen antes referencia. Para non ter que debuxar cada parcela e sinalar os lindeiros -confrontacións-, ocorréuselle o

9 Sobre o espallamento das patacas e os conflitos que o seu cultivo motivou, vid. Rodríguez Galdo/Dopico (1980: 11-37).

${ }^{10}$ Só así pode explicarse o vigor da sociabilidade mantida en aldeas e parroquias ata o século Xx. Diso tratamos parcialmente en Saavedra (1992 $3^{\mathrm{a}}$ parte). 
que el chama método de agros (por agras), que consistiría en mencionar as leiras coas súas medidas e declarar en que agro estaban. As razóns que alegaba eran poderosas. Por agro, campo, vega ou partido, afirma «se entiende de un grande pedazo de tierra dentro de un término, feligresía o lugar, que esté unido, contiguo y continente, en que precisamente hay y se hallan muchos poseedores, que tienen partes intermixtas, o interpoladas, sea un terreno abierto, o en otra cualquiera manera, de foro o del común». Dentro de cada agro, as parcelas de cada cultivador

(...) se dividen y subdividen en concas y puñados, y todas están interpoladas e intermixtas entre innumerables poseedores (...). Y si se hubiera de describir cada minutísima porcioncilla con todas las multiplicadas confrontaciones por los cuatro vientos, subirían a millones de millones los renglones que llevarían solo los asientos [declaracións], y en todo se aumentaría el embarazo y la mayor compresión al menor transcurso por la variación tan contingente de nombres, univocación de ellos y vicisitud de diversos poseedores; de suerte que no habrá mañana cosa más dudosa que buscar una conca de tierra por la confrontación que hoy tenga (...), y será muy fácil hallarla siempre como se describa unida, continente y comprehendida en un agro ${ }^{11}$.

A organización en agras facía necesaria en todas partes, e máis nas comarcas de agricultura intensiva e acusada parcelación, unha disciplina colectiva que só a fortaleza e solidariedade da comunidade aldeá podían manter ao longo de xeracións. Asemade, o feito de que dentro das agras, dun ano para outro, as leiras se partisen, vendesen, trocasen, cambiando de posuidor, sen que en moitas ocasións quedase constancia escrita, acredita o valor da oralidade á hora de dar fe as mudanzas: chegaba con que os veciños as coñecesen e, chegada a ocasión, testemuñasen delas. Neste e noutros aspectos, Galicia parecíalles aos responsables do Catastro de Ensenada «muy diversa que las demás provincias», e as dimensións e figuras das parcelas eran mutantes: «Y por estas señas [lindeiros] en un año de diferencia nunca [se] podrá asegurar alguna hipoteca, cuyo asunto en este Reino se gobierna por otras reglas, pues están los foros y cargas sobre confusos

${ }^{11}$ Arquivo Xeral de Simancas, Dirección Xeral de Rendas, $1^{\text {a }}$ Remesa, mazo 1.874 (1752). 
y dilatados agros, [y] las suele pagar el que nada posee y cobrar al que nada tiene» ${ }^{12}$.

\section{OS MONTES COMUNAIS}

A finais do século XVIII, as terras dedicadas a labradío, prados, viñas e soutos non superaban o vinte por cento da extensión total do Reino. Catro quintas partes da superficie galega eran montes, uns poucos particulares e normalmente pechados, e a maioría abertos e comúns, aínda que en ocasións o aproveitamento comunal só se autorizaba para pastos e recollida de leña. Nos resumos ou mapas xerais do Catastro de Ensenada unicamente figuran unhas 425.000 hectáreas de monte, o $11,6 \%$ da extensión real do Reino (e o $50 \%$ escaso da superficie catastrada); foron excluídas, xa que logo, preto de dous millóns de hectáreas, en boa medida porque os veciños declaran que eran «inútiles por natureza». Isto constituía unha mentira -moi propia de fontes fiscais-, pois non había monte tan fragoso que non dese algo de leña, pastos, carbón ou pedras, e de feito o comunal constituía un espazo dominado, apropiado polos veciños, segundo pon de manifesto a toponimia menor ${ }^{13}$.

Abel Bouhier, na súa magna obra Galicia, definiu o monte, con grande acerto, como o soporte do sistema, ou sexa o soporte de todo o complexo agropecuario, porque grazas aos recursos que ofrecía, desde estrume para esterco ata colleitas de centeo e trigo, pastos e leñas, podían funcionar e reproduciríanse as pequenas explotacións (Bouhier 2001: II 755 ss; Balboa 1992; Saavedra 1996b). Por iso, o monte non era algo oposto ao labradío, senón a súa continuación, e os usos de bravo e manso mantiñan unha estreita relación e dependencia. Na paisaxe,

${ }^{12}$ Ib., no mesmo informe anterior. Cómpre dicir que para fortuna -e traballo- dos historiadores e sobre todo dos estudosos da toponimia, o método de agros non foi aprobado pola Real Xunta da Única Contribución, polo que os subdelegados do catastro tiveron que asentar nos chamados libros reais os datos completos de cada parcela (tamaño, dedicación, calidade, localización, lindeiros...).

13 A toponimia menor dos montes non se rexistra apenas no Catastro de Ensenada, pois foron declarados en grandes bloques na meirande parte das parroquias, sen que adoiten figurar os nomes de penas, fontes, recunchos, etc. 
as terras de cultivo continuo e os espazos comunais diferenciábanse con claridade, como se non tivesen nada que ver. $\mathrm{Na}$ realidade o que existía era unha unión inextricable.

Podemos tratar de medir en ferrados ou hectáreas as superficies dedicadas a monte en diferentes épocas, pero non resulta posible cuantificar os múltiples recursos que o comunal lles proporcionaba aos veciños de aldeas e parroquias. Neste punto, a información cualitativa di en non poucas ocasións máis que as estatísticas. Así, un autor descoñecido da década de 1840 conta como os peches de montes nas Rías Baixas deixaran sen modo de vida as familias bodegueiras, que antes criaban unhas ovellas e vendían feixes de leña (Pensado 1995):

He conocido - di- a familias que con unas seis ovejas que llevaban al monte (...) que por allí [O Salnés, O Morrazo] se extendía, y con los carrascos que allí arrancaban se vestían y sacaban un jornal diario para sustentarse. Benito Barral, (a) el Pesco de la Esfarrapada, que murió de más de ochenta años, se mantuvo hasta cerca de morir con haces crecidos de carrascos, cuyo peso sobre las espaldas le hacía andar muy encorvado. Decía con cierta conformidad humilde: Este é o men trigo.

A importancia que tiñan os montes queda tamén de relevo en que a historia de moitas comunidades campesiñas ten as súas principais epopeas na defensa que os veciños facían do comunal fronte a outras aldeas e parroquias, fronte aos señores e fronte ás autoridades locais. Nas concordias, convenios e poderes pasados por diante de escribán, así como nos preitos levados á Real Audiencia e nos arquivos que pertenceron a institucións eclesiásticas e casas nobres consérvase abondosa información sobre os conflitos orixinados polo aproveitamento e titularidade dos montes, proba inconcusa do valor que para o grupo veciñal tiña ese altro modo dipossedere, como diría Paolo Grossi (Grossi 1977). A memoria colectiva conservaba ao longo de xeracións vigorosa noticia das agarradas e preitos ruidosos sostidos polos devanceiros por mor do comunal; de pais a fillos dentro de cada familia e de vellos a novos en cada aldea transmitíanse os saberes agrarios e toda unha cultura na que as servidumes e aproveitamentos comunitarios ocupaban un lugar central. Como ten escrito con perspicacia Edward P. Thompson (1979: 146), os labregos herdaban non só unhas determinadas terras, senón tamén unha certa psicoloxía social e comunal da propiedade: os dereitos e servidumes comunais, sinala, formaban un delicado equilibrio agrario que dependía 
non só do dereito herdado, senón tamén da estrutura herdada de costumes e controis dentro da cal se exercía ese dereito (...). O beneficiario herdaba tanto o dereito como a malla sobre a que se facía efectivo; en consecuencia, debía herdar tamén un certo tipo de psicoloxía social e comunal da propiedade: a propiedade non só da súa familia, senón da súa familia dentro da comunidade.

O monte era un alicerce da cultura comunitaria e un factor decisivo de identidade local no ámbito da aldea ou da parroquia. A súa defensa servía para afirmar e reforzar a unidade dos veciños e mesmo asegurar a condición de tales, e non é raro atopar enfrontamentos violentos entre os dunha aldea ou unha parroquia e os forasteiros, empregando nas agarradas certos ritos e formalidades para marcar as fronteiras que era necesario respectar. Así, cando en 1798 os campesiños de Fontefría e Servoi (Xunqueira de Ambía) resolveron impedir aos de Piornedo sementar centeo nunha roza, achegáronse «agavillados, con tumulto [e] algazara, asistidos de milicianos armados de la plaza de Monterrei, a distancia de dos leguas, tocando con músico gaitero su tambor, con amenazas y que saliesen al campo los vecinos de este dicho lugar [Piornedo], para experimentar por quién quedaba la lucha» (Saavedra 1994: 91-92). As prendas de gando tiñan asemade un claro significado ritual, aínda que algunhas autoridades civís e eclesiásticas as notasen de abusos, alborotos e desenfreos levados a cabo por corsarios terrestres, que coas multas que lles cobraban aos propietarios do gando mercaban carne e viño para comidas e embriagueces colectivas. O abade ourensán don Pedro González de Ulloa (1950: 29-30) declaraba en 1777 como tentara de acabar con este costume dos seus fregueses:

(...) uno de los asuntos en que suelen ocupar los días festivos estas gentes del bronce -di-, es el multar a su arbitrio los ganados mayores y menores del contorno que pasan fuera de los límites respectivos. Esto se hace por entre semana; deposítase lo que se exige, y en llegando el día festivo el juez pedáneo junta al concejo, vanse a la taberna, y allí... Llegan los dueños del ganado a desempeñar las prendas que se dieron antes para libertar las reses encorraladas; encuentran a los congregantes como convidados a las bodas de Peritoo; empiezan a trabarse de la lengua y luego de las manos... El escandaloso desenfreno que motivaba este abuso... me obligó a pedir despacho del fiscal de la Coruña para contener tales excesos. Logréle, porque no he podido contenerles por la justicia ordinaria... ;Oh, y lo que hubo cuando se les hizo saber! Si se les reprenden estos abusos dicen que es uso y costumbre... 
Pero a natureza xurídica dos montes galegos era diversa, e con ela variaba tamén a forza da casa e a da comunidade veciñal. Normalmente, o Catastro de Ensenada fala de montes comunes ou de emolumentos del común, e informa - con grandes ocultacións- dos ferrados de superficie que entran nesa categoría de bens dentro de cada parroquia. Pola documentación xudicial, señorial e notarial sábese, porén, que ao sur dunha liña que iría de Quiroga á desembocadura do Ulla predominaban os montes que poden chamarse en rigor comunais, pois a súa propiedade -cando menos, no tocante ao usufruto- correspondía ao grupo veciñal, xa fose a aldea, a parroquia, ou inclusive toda unha xurisdición. $\mathrm{O}$ aproveitamento implicaba non poucas veces o pagamento dunha renda aos donos da xurisdición ou do directo dominio -que podían ou non ser os mesmos-, e a propiedade dos montes era a miúdo motivo de litixio entre concellos e señores, pero iso non debe escurecer algo fundamental: que pagando ou de xeito gratuíto, o acceso ao usufruto dos montes derivaba de razóns de veciñanza. En efecto, chegaba con ter lume aceso para poder participar en igualdade en todos os aproveitamentos do monte, desde a leña ata pastos e rozas. Claro que a igualdade legal encubría moitas veces desigualdades materiais, pois os que non tiñan gando non se servían dos pastos e mesmo atopaban dificultades para cavar e sementar a roza que lles correspondía no sorteo, ao non disporen dunha parella de vacún (Balboa 1992).

A fortaleza dos concellos do sur de Galicia, e moi especialmente da provincia de Ourense, nacía en boa medida da natureza verdadeiramente comunal dos montes abertos; o seu aproveitamento regulábase en xuntanzas dos cabezas de casa, e calquera matrimonio novo que acendese lume adquiría os mesmos dereitos que tiñan os veciños antigos. O comunal non se podía vender, agás por decisión tomada en concello aberto. Sirva de exemplo o acontecido no Couto de Cernego e en Vilamartín de Valdeorras, onde algúns veciños fixeran vendas e trocos de montes forais na década de 1860: primeiro a Audiencia da Coruña e despois o Tribunal Supremo anularon todo, dándolles a razón aos que tal cousa pediran, porque «los montes comprendidos dentro del referido coto redondo de Cernego nunca se habían dividido por más que fueran forales, pagándose la renta por capitación fija y únicamente por los vecinos de la parroquia, sin que pudiesen continuar en el aprovechamiento cuando mudaban de domicilio, ni 
mucho menos traspasarlo, lo cual probaba su calidad comunal, y por consiguiente sólo el pueblo, con las autorizaciones determinadas por las leyes, podía enajenar.... ${ }^{14}$.

A fortaleza das comunidades de aldea de Ourense parece, en resumo, moi superior á que tiñan ás do norte de Galicia, e na documentación xudicial hai probas disto. O mesmo tamaño dos núcleos de hábitat -grande, segundo os parámetros galegos-, a estrita regulación das actividades agropecuarias coa existencia en ocasións de veceiras, a vixencia de foros colectivos -subscritos polos concellos e non por cada colono en particular- e a natureza autenticamente comunal dos montes constituían factores que reforzaban a cohesión da comunidade; fóra dela non se entendería a vida campesiña ${ }^{15}$ (Fariña Jamardo 1982: caps. I e VIII).

$\mathrm{Na}$ metade setentrional de Galicia, os montes dos concellos que se usufrutuaban pola simple razón de veciñanza eran escasos nos séculos da Idade Moderna, e en cambio predominaban con moito os montes de varas ou de voces que, aínda que estaban abertos e pro indiviso, considerábanse anexos a determinados casais ou, mellor, a determinadas liñaxes, herdeiros e porcioneiros, en realidade propietarios consorciados, que podían vender as súas partes. Para pasto e leña estilábase que fosen usados por todos, pero á hora de facer rozas, a cada casa de aldea adxudicábanselle as súas varas, ou non se lle adxudicaban, caso de non as ter; o feito de acender lume non era aquí abondo, a diferenza do que ocorría no sur. Compréndese doadamente que este réxime de explotación proporcionaba menos cohesión social que o descrito anteriormente; era máis desigualitario e correspondía a unha poboación máis diseminada, aínda que tamén menos asoballada quizais polo señorío. Certamente, os montes comunais dunha parroquia, dunha aldea, ou de varias aldeas non eran tampouco aquí descoñecidos por completo, pero ocupaban minguada extensión (Bouhier 2001: II 786 ss.).

Co que queda dito, agardo ter clarificado ou salientado a diferenza entre os montes de varas e os municipais ou de mancomún, usufrutuados os últimos en razón de veciñanza. Estes, de aproveitamento en principio máis democrático e que non se poden vender por iniciativa

\footnotetext{
${ }^{14}$ Colección Legislativa. Sentencias del Tribunal Supremo, 1865, 184-191.

${ }^{15}$ Insistiu nestas realidades en Fariña Jamardo (1982: caps. I e VIII, en particular).
} 
individual, son realmente comúns; os de varas, permanecen abertos e pro indiviso, pero constituían de feito unha propiedade consorciada, anexos ás casas dunha aldea en proporción determinada; un propietario está en condicións de vender a súa parte ou de abandonar o seu lume sen perder por iso o dereito ao usufruto da cota, e daquela, ben que os montes correspondan a predios dunha aldea e definan un territorio, por compras ou herdos un veciño doutro lugar chega a adquirir en ocasións algunhas varas neles. A un matrimonio novo que levante unha casa non se lle permitirá facer rozas se algún dos seus compoñentes non é herdeiro, a menos que efectúen unha adquisición neste sentido ou se lles faga unha concesión gratuíta, o que non é norma. Como dixemos, a cohesión social non pode ser a mesma nas distintas partes de Galicia; a intensidade da vida dos concellos, diferente ao norte e ao sur, traducía variacións na organización agraria, no poboamento, na representación e forza da casa, e no papel da comunidade. De xeito simplificado, cabería dicir que na Galicia central e setentrional, de pequenos asentamentos e montes de varas, a casa tiña unha forza maior e a comunidade menor; na Galicia meridional, de aldeas grandes e montes municipais, acontecía ao revés, a ideoloxía da casa estaba menos enraizada e o sentimento comunitario era máis intenso.

\section{AS ESTRUTURAS FAMILIARES E A HERDANZA}

As fontes estatísticas do XVIII e XIX poñen de manifesto que no tamaño e estrutura dos grupos domésticos existían en Galicia diversidades e fronteiras culturais moi evidentes, pero que non coinciden nin coas da organización agraria nin coas do hábitat nin coas dos montes comunais. De modo resumido, pode dicirse que tanto no Catastro de Ensenada (1752) como no censo de 1860 aparecen dúas Galicias: a representada pola antiga provincia de Lugo (que case se correspondía coa actual diocese) e todo o territorio restante. O que non sabemos é se no XVI e comezos do XVII existían esas fronteiras ou se, de existir, eran tan marcadas.

As diferenzas consistían en que na antiga provincia de Lugo as familias se compuñan dun número de persoas por riba de cinco, e que dun corenta a un cincuenta por cento delas eran de estrutura complexa -é 
dicir, que á parte dos pais e fillos había outras persoas: celibatos, xenros ou noras-, apenas existían persoas vivindo soas e os fogares que tiñan á fronte unha muller tamén eran escasos. Pola contra, nas provincias de Mondoñedo, Betanzos, A Coruña, Santiago, Tui e Ourense o número de habitantes por fogar situábase polo regular entre 4 e 4,5 -e ás veces inclusive menos de catro-, as familias nucleares -pais e fillos solteiros- acadaban os dous terzos do total, as complexas representaban arredor da quinta parte, non era raro que houbese persoas vivindo soas e tampouco que existisen fogares gobernados por mulleres, nomeadamente por viúvas (Dubert 1992: 157-260).

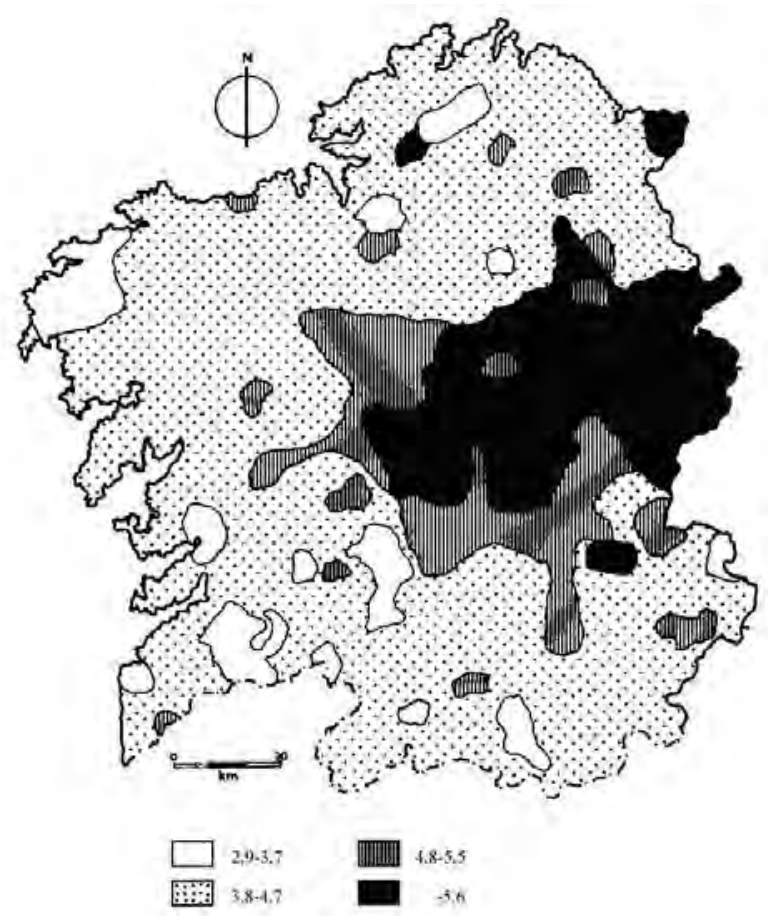

Mapa 3. Número de persoas por fogar a mediados do XVIII. Tomado de Dubert (1992: 87).

As diferenzas no tamaño e na composición das familias non quedaban reducidas á cuestión só de número. Detrás das variables estatísticas acochábanse distintos conceptos da casa e da comunidade, das relacións entre pais e fillos e entre homes e mulleres e das formas de 
repartir a herdanza. Nas terras luguesas o primoxénito adoitaba recibir a mellora de terzo e quinto, coa finalidade de que o patrimonio familiar non se dividise, e os roles dos fillos viñan determinados polo sexo e pola orde de nacemento: o máis vello sabía que, polo común, sería o mellorado e que, en contrapartida, tería a obriga de coidar e funerar os pais e amparar os irmáns e irmás célibes que permanecesen na casa patrucial. As familias, por mor da elevada proporción de celibatos que creaba a mellora, eran de tamaño considerable e estaban moi xerarquizadas internamente, pois o patrucio e o primoxénito ou mellorado tiñan unha posición de privilexio con respecto aos outros membros.

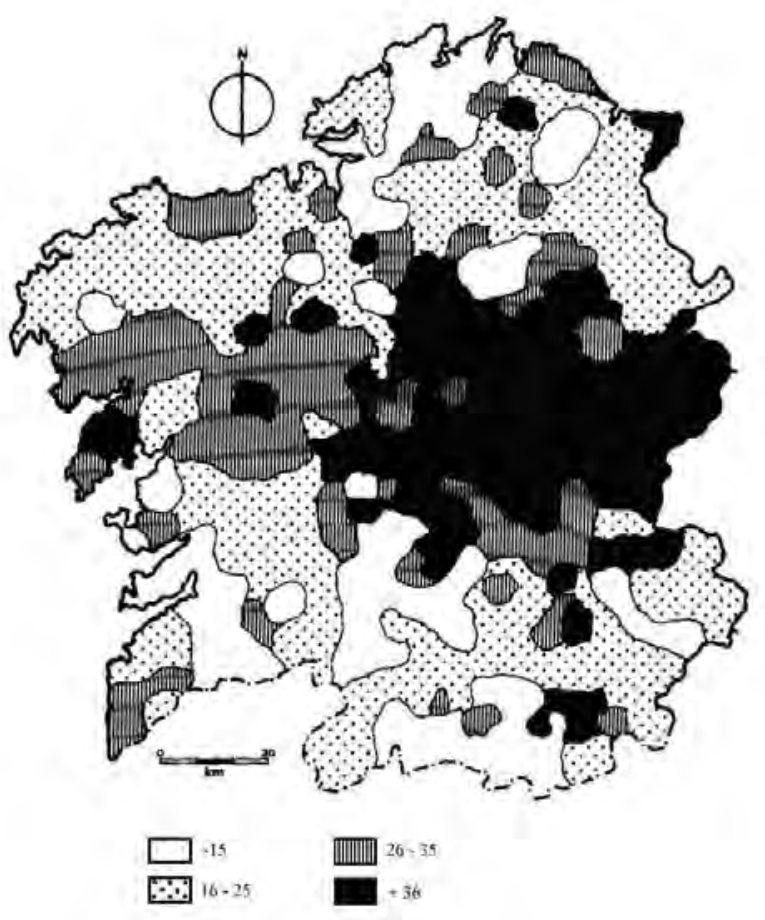

Mapa 4. Porcentaxe de familias con estrutura complexa a mediados do XVIII. Tomado de Dubert (1992: 103).

A discriminación que introducía entre os irmáns o sistema de mellora longa había que xustificala a través da defensa da ideoloxía da casa, un patrimonio material e inmaterial que era preciso conservar e, de ser 
o caso, agrandar, e a esta finalidade había que sacrificar os intereses persoais, en particular os dos celibatos, discriminados no repartimento dos bens e sen posibilidades reais de matrimoniar. A casa viña ser, no imaxinario, algo permanente, ocupada hoxe por unha xeración e mañá por outra. Neste contexto, a comunidade estaba constituída por unha federación de casas, empeñadas en evitar que o número de veciños aumentase demasiado, pois diso resultaba un incremento dos usufrutuarios dos montes de varas, algo que trataban de evitar os patrucios das casas antigas (Saavedra 1996).

Fóra da provincia de Lugo, o sistema de herdanza caracterizábase pola flexibilidade e orientábase cara a un modelo preferencial, ou sexa, unha curta mellora a favor do fillo ou filla que quedaba na casa para coidar dos pais. As mulleres tiñan as mesmas, e ás veces maiores, posibilidades de recibir esa mellora, e os pais elixían, sen esperar a se atopar in articulo mortis, o descendente que eles preferían, cousa que provocaba competencia entre os irmáns. A xerarquización interna da familia non era tan acusada como nas terras luguesas nin tampouco a subordinación da muller: o feito de que as fillas puidesen recibir a mellora curta e as viúvas dirixir o fogar así o evidencia. A idea da casa non se atopaba asemade tan asumida coma en Lugo, e os fillos e fillas que non podían quedar cos pais establecíanse á parte -as mulleres- ou emigraban -os homes-, por iso non resulta raro atopar fogares nos que vive unha soa persoa, e abundantes matrimonios de bodegueiros que traballaban unhas escasas terras e andaban a xornal ou ocupados nun oficio (Fernández Cortizo 1991, 1992, 2001). Deste xeito, se a familia se atopaba internamente menos xerarquizada que en Lugo, a comunidade estábao máis, precisamente pola abundancia de bodegueiros e bodegueiras (coñecidos tamén, segundo as comarcas, por caseteiros/as, camareiros/as).

$\mathrm{O}$ dereito que regulaba as relacións familiares, desde o matrimonio ata a transmisión do patrimonio, era o mesmo en toda Galicia, pero as prácticas culturais concretas marcaban fronteiras internas entre os territorios de familias complexas, sistema de mellora longa para evitar a división do patrimonio e forte ideoloxía da casa, e as provincias de familias nucleares e pequenas, modelo de herdanza preferencial -que favorecía as partillas- e menor enraizamento da idea da casa. Trátase de prácticas diferentes que a mediados do século XVIII se acomodaban ben a economías familiares variables nas fontes de ingresos e nos 
modos de aproveitamentos dos recursos agropecuarios: na provincia de Lugo, o sistema agrario tiña carácter extensivo, e unha familia non podía subsistir sen abundante forza de traballo humano e animal; no litoral, a agricultura intensiva permitía que unha parella ou unha persoa soa puidese vivir cultivando unhas leiras, e ademais existían ocupacións moi importantes para as mulleres, caso do téxtil (traballo nos lenzos, de palilleiras...). En Ourense a emigración por uns anos e os oficios ambulantes proporcionábanlles a moitas familias uns ingresos que non sempre quedan á vista nas fontes documentais ao uso. Polo tanto, para entender as diversidades na organización familiar e no sistema de herdanza hai que razoar en termos de patrimonio agropecuario, pero tamén de actividade, pois en moitas comarcas as economías campesiñas tiñan unhas fontes de ingresos moi diversificadas (Carmona 1990: 65-83).

Hai que sinalar, finalmente, que as investigacións das que se dispón apuntan a que foi no decorrer do XVII cando se xeneralizou na antiga provincia de Lugo o sistema de mellora e as estruturas familiares complexas, e con elas a ideoloxía da casa, como elemento xustificador da discriminación dos fillos no acceso ao patrimonio e ao matrimonio. Tamén é preciso reparar en que a finais do XVIII, coa renovación do sistema agropecuario, se flexibilizaron as prácticas hereditarias, por iso o número de veciños das aldeas do interior aumentou moito entre 1752 e 1860 (Sobrado 2001: 400 ss.) ${ }^{16}$. E porén, no imaxinario mantivéronse ata dobrado o século $\mathrm{XX}$ as fronteiras entre as terras de mellora e as de partilla, e nas primeiras conservouse como ideal a mellora, a transmisión íntegra do patrimonio e o valor da casa. $\mathrm{O}$ ideal e o real non sempre coincidían, pero moitas veces o ideal era tamén real ${ }^{17}$.

\footnotetext{
${ }^{16}$ Recolle unha interesante análise da evolución do sistema hereditario.

${ }^{17}$ Vid. as consideracións de Lisón Tolosana (1974 e 1981) onde analiza as fronteiras culturais entre Lugo e Ourense no tocante ao concepto de casas e ás prácticas hereditarias no século Xx.
} 